\title{
The Regular Research of Stress Level for Vertical Displacement of
}

\section{Loess}

\author{
Kangfeng Yuan ${ }^{\mathrm{a}}$ \\ (Shanxi Provincial Research Institute of Communications, Shanxi Key Laboratory of Geotechnical \\ and Underground Engineering, Shanxi, Taiyuan 030006) \\ ayuankangfeng@163.com
}

Key words: Vertical displacement; Stress level; loess; Water content; pressure

Abstract. At present, the research is not enough for the vertical displacement and stress level in domestic.The paper aims how the law between the vertical displacement and stress level by shear test for loess.The results showed that: under the high shear stress level,the effect of soaking sample of vertical deformation is large. When the water is fully infiltrated, the primary structure of the loess is destroyed and the vertical displacement increases rapidly.In the process of wet shear test, the vertical displacement is mainly caused by the deformation of the collapse.

\section{Introduction}

Loess special sensitivity to water has always been the research center of loess mechanic characteristic.In recent years, there are more and more depth study of loess deformation characteristics.And has obtained certain achievement. WANG Shuo et $\mathrm{al}^{[1]}$ propose that the cohesion of unsaturated remolded loess will increase with the increment of dry density due to the influence of reciprocity of particles and tension action of inter-granular water, showing an index change.Internal friction angle of unsaturated remolded loess gets a little increase with the increment of dry density, approximately showing a linear variation.ZHANG Jun ran et $\mathrm{al}^{[2]}$ think that other conditions are the same, the samples experienced drying-wetting cycle have higher relationship of stress ratio-strain, higher strength,smaller volumetric deformation than the sample not experienced drying-wetting cycle.The samples experienced drying-wetting cycle have low saturation but high relationship of stress ratio-strain and strength. It is because larger suction experienced previously which is equivalent to larger effective pressure experienced, that makes the sample to become over consolidated state. WANG Hui et $\mathrm{al}^{[3]}$ think that the permeability coefficient of intact loess assumes a decreasing tendency along with penetration time extension.The intact loess microstructure is destroyed after disturbance and remodeling. And dry density changes have a significant impacton penetration coefficient which tends to decrease while the dry density increases.In the previous research, the study of vertical displacement of the loess humidifying shear have less research ${ }^{[4]-[10]}$.

With the help of shear tests to research the characteristics of loess for different stress level and different water content, coming up with some conclusions. The research have certain theoretical significance for the study of loess properties. 


\section{The loess of test}

The loess of tests is taken from certain foundation at the Jinnan district, in a depth of $6 \mathrm{~m}$ below the surface, which is silty clay, with a small amount of worm holes. The soil samples have been whittled to length $35 \mathrm{~cm} \sim 45 \mathrm{~cm}$ cube in the field.The natural moisture content of soil samples was $9.5 \%$, through the burette method to configure the required moisture content for the sample.

\section{Test Instruments and Test Method}

\section{Test Instruments}

The test instrument is the conventional direct shear apparatu.Through the improvement of instrument application,make the strain type apparatu into stress type, which can realize some stress conditions of humidifying direct shear test.

\section{Test Method}

Prepare eight original state compression sample (diameter $6.03 \mathrm{~cm}$, height $2 \mathrm{~cm}$ ). The vertical pressure of test is $200 \mathrm{kpa}$ and $400 \mathrm{kpa}$, with the humidifying direct shear test to measure the law of vertical displacement and moisture content.Installed the vertical load, until the need of the vertical pressure, compression after stability, start the motor, began to shear and shear stress at a certain stress of $0.3,0.4,0.5,0.6$ times of the stress level. In the process of shearing by water flooding until sample shear failure or shear stability.The stability criteria for displacement increment is less $0.01 \mathrm{~mm}$ for ten minutes.

\section{Test Results and Analysis}

In the condition of the vertical pressure $50 \mathrm{kpa}$,the affect law of different stress level for vertical displacement is indicated in figures 1 to 4 :
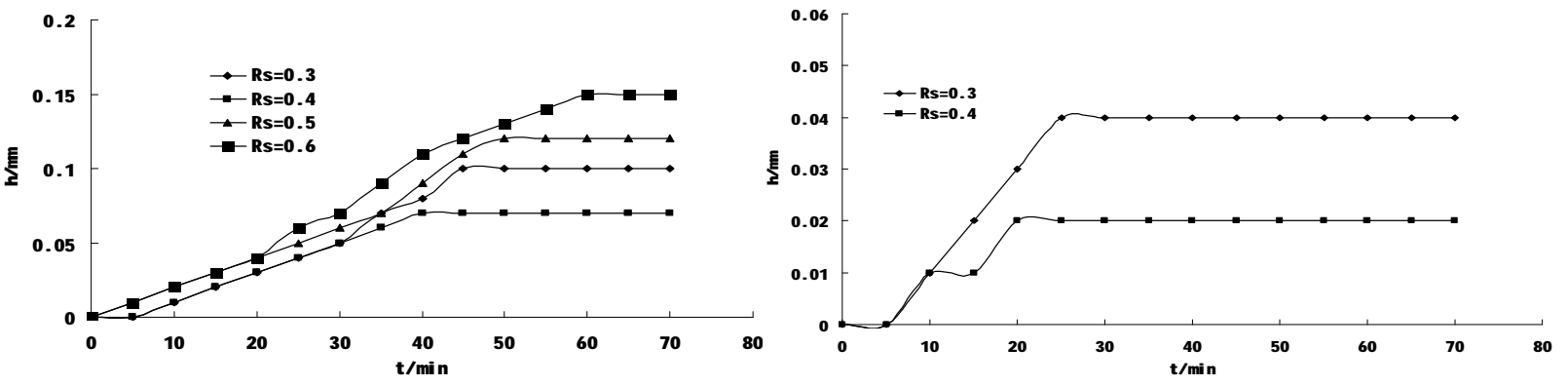

Figure 1. The shear curve for $\mathrm{w}=8 \%$ to $\mathrm{w}=10 \%$

Figure 2. The shear curve for $\mathrm{w}=10 \%$ to $\mathrm{w}=12 \%$
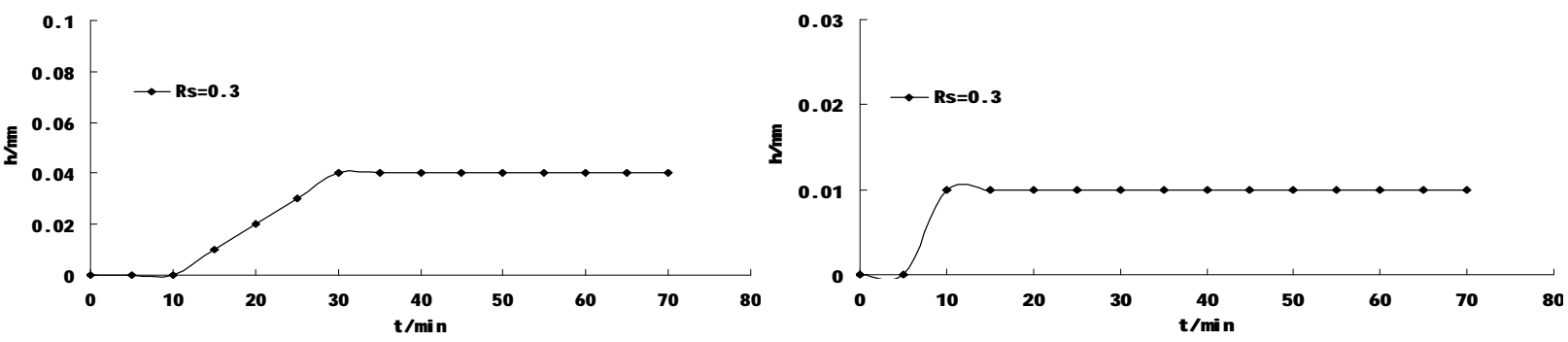

Figure 3. The shear curve for $\mathrm{w}=12 \%$ to $\mathrm{w}=14 \%$

Figure 4. The shear curve for $\mathrm{w}=14 \%$ to $\mathrm{w}=16 \%$

Figure 1-4 shows that under the high shear stress level,the effect of soaking sample of vertical deformation is large.This is due to the high shear stress more damaged on the loess structural.And the 
weakening of the structure will produce large vertical deformation.

In the condition of the vertical pressure $100 \mathrm{kpa}$,the affect law of different water content for vertical displacement is indicated in figures 5 to 8 :
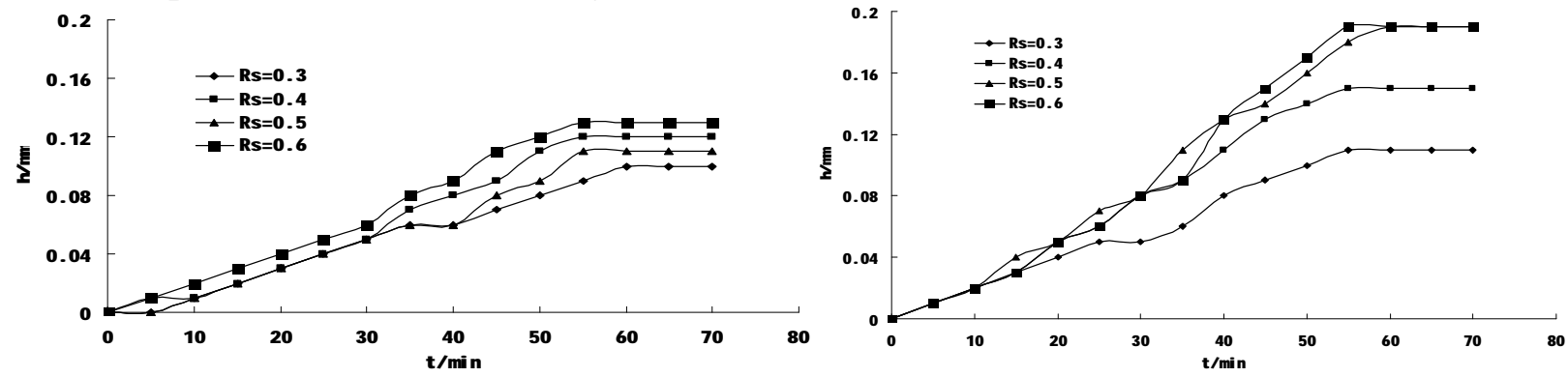

Figure 5. The shear curve for $\mathrm{w}=8 \%$ to $\mathrm{w}=10 \%$

Figure 6. The shear curve for $\mathrm{w}=10 \%$ to $\mathrm{w}=12 \%$
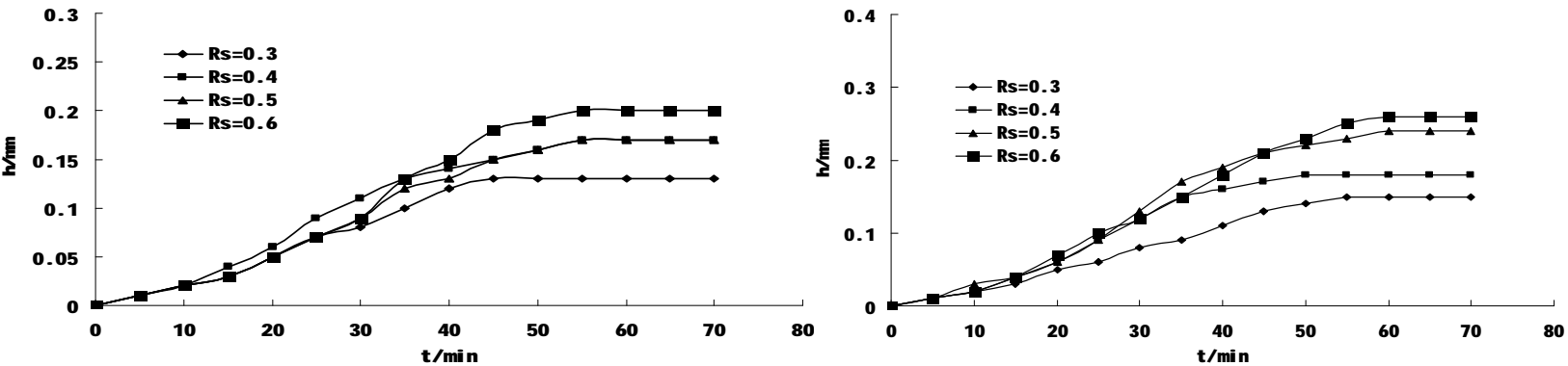

Figure 7. The shear curve for $\mathrm{w}=12 \%$ to $\mathrm{w}=14 \%$

Figure 8. The shear curve for $\mathrm{w}=14 \%$ to $\mathrm{w}=16 \%$

Figure 5-8 shows that when the water is fully infiltrated, the primary structure of the loess is destroyed and the vertical displacement increases rapidly. In the process of wet shear test, the vertical displacement is mainly caused by the deformation of the collapse.

\section{Conclusions}

In this paper, direct shear apparatu is applied to study properties of loess. The main conclusions are as follows:

(1) Under the high shear stress level,the effect of soaking sample of vertical deformation is large.This is due to the high shear stress more damaged on the loess structural.And the weakening of the structure will produce large vertical deformation.

(2) When the water is fully infiltrated, the primary structure of the loess is destroyed and the vertical displacement increases rapidly. In the process of wet shear test, the vertical displacement is mainly caused by the deformation of the collapse.

\section{Acknowledgements}

The paper is Sponsored by the Basic Research Project of Shanxi Province [2014021033-2].

\section{References}

[1] WANG Shuo, LIU Zhan-hui. Test Study on Influence Factor of Shear Strength of Unsaturated Remolded Loess [J]. JOURNALOF SHIJIAZHUANG TIEDAO UNIVERSITY (NATURAL SCIENCE), 2010,23(3): 86-89(in Chinese).

[2] ZHANG Jun-ran,XU Qiang, SUN De-an. Effect of suction history on mechanical behavior of unsaturated soils [J]. Rock and Soil Mechanics, 2013,34(10): 2810-2814(in Chinese).

[3] WANG Hui, YUE Zu-run, YE Chao-liang. Experimental Investigation of Permeability Characteristics of Intact and Reshaped Loess [J]. JOURNALOF SHIJIAZHUANG RAILWAY INSTITUTE (NATURAL SCIENCE), 2009,22(2): 20-22(in Chinese). 
[4] SONG Fei. The study on the stability and deformation mechanism of huazicun loess landslide [J].SHANXI SCIENCE \& TECHNOLOGY of COMMUNICATIONS, 2012,216(3):13-15 (in Chinese).

[5] LI Xu-hua.The Rational Slope Type Research on Loess High Slope [J].SHANXI SCIENCE \& TECHNOLOGY of COMMUNICATIONS, 2012,214(1):29-30(in Chinese).

[6] LIAO Xiong-hua, WANG Lei-xiao, ZHANG Ke-xu et,al. An inelasto-plastic constitutive model for soil[J]. Rock and Soil Mechanics, 2002(1):41-45(in Chinese).

[7] TANG Xin-fu, ZHAO Yun-gang. Effects of Moisture Content on the Shear Strength of a Compacted Clay [J].Metal materials and metallurgy engineering,2009,37(3):49-53(in Chinese).

[8] GONG Bi-wei, ZHOU Xiao-wen, ZHOU Wu-hua. Teston suction and strength of expansive soil in a desorption-absorption cycle of moisture[J]. Chinese Journal of Geotechnical Engineering, 2006, 28(2): 207-209(in Chinese).

[9] SHENG Wei-gao,LI Guo-wei,YUAN Jun-ping. Stability analysis of high slopes based on the influence of water content change on soil strength [J]. Advances in Science and Technology of Water Resources, 2009,29(1):12-15(in Chinese).

[10] WHEELER S J, SHARMA R S, BUISSON M S R.Coupling of hydraulic hysteresis and stress-strain behavior in unsaturated soil[J]. Geotechnique, 2003,53(1):41-54. 